\title{
Simulation and Analysis of Direct-driven Wind Turbine
}

\author{
http://dx.doi.org/10.3991/ijoe.v11i5.4710 \\ Hu Hao, Gu Bo, Ren Yan and Huang Hui \\ North China University of Water Resources and Electric Power, Zhengzhou, China
}

\begin{abstract}
Direct-driven wind turbine has become one of the mainstream technologies in wind power generation. Studying the system structure and the control technology of direct-driven wind turbine is the basis for optimization operation of direct-driven wind turbine. The system structure of direct-driven wind turbines is analyzed and the main subsystem mathematical model of direct-driven wind turbine are established, including wind speed model, aerodynamic model, generator model, and grid side converter model. The overall model of direct-driven wind turbine is established by integration of each subsystem mathematical model. The overall model of the direct-driven wind turbine is modeled and analyzed, and the simulation results show that the direct-driven wind turbine model can accurately reflect the dynamic characteristics of the directdriven wind turbine operation process.
\end{abstract}

Index Terms-direct-driven wind turbine; control technology; mathematical model; dynamic characteristics

\section{INTRODUCTION}

With the gradual development of wind power technology, especially the development of large power converter technology, full power converter wind turbines have gradually become the mainstream model of wind power. Direct-driven wind turbine as a full power converter wind turbines have been obtained the widespread application. Therefore, studying the system structure and the operation principle of direct-driven wind turbine, is one of the main ways to improve the operating efficiency of direct -driven wind turbine.

Rolan et al. [1] analyzed the advantages of the directdriven wind turbine, established the wind speed model, the aerodynamic model and the generator model. These model were simulated and analyzed, the results show that these model can reflect the operating characteristics of the direct-driven wind turbine in a certain extent. Kim et al. [2] analyzed and simulated the direct-driven wind turbine control system and presented a direct-driven wind turbine reactive power control algorithm, so as to provide reactive power support for grid. The converter is an important component of the direct-driven wind turbine, therefore, research on the control algorithm of the full power converter is the basis for the stable operation of the direct-driven wind turbines [3-4]. Tiwari et al. [5-6] modeled and analyzed the direct-driven wind turbine using MATLAB/SIMULINK toolbox, which further promotes the study of the direct-driven wind turbine technology. Jayalakshmi et al. [7-8] analyzed the running characteristics of the grid type direct-driven wind turbines, and established the corresponding simulation model, which provides support for the grid control technology research of the direct-driven wind turbines. Janani et al. [9] analyzed and modeled the small directdriven wind turbine running principle, which Provides the foundation for the application of the small direct-driven wind turbine. Large direct-driven wind turbines are the development direction of the direct-driven wind turbine. Studying the large direct-driven wind turbine operating principle and control scheme are to provide support for the application of the direct-driven wind turbine [10].

Based on the existing direct-driven wind turbine research, the system of the direct-driven wind turbine are analyzed. The mathematical model of the direct-driven wind turbine main subsystems are established, including wind speed model, aerodynamic model, generator model, the grid side converter model. The whole model of the direct-driven wind turbine is established by integrating each subsystem mathematical model. The dynamic characteristics of the direct-driven wind turbine are studied and analyzed.

\section{WIND SPEED MODEL}

Before the system mathematical model of the directdriven wind turbine is established, the overall structure of the direct-driven wind turbine is analyzed firstly. The overall structure of the direct-driven wind turbine is shown as Figure 1.

The direct-driven wind turbine includes the rotor, the direct-driven permanent magnet synchronous generator (PMSG), the converter (including machine side converter and grid side converter), the direct-driven wind turbine control system, the power grid and other parts. The rotor is to convert the wind energy into the mechanical energy. For the direct-driven wind turbine, the rotor is directly connected to the direct-driven permanent magnet synchronous generator, so the gear box is no longer needed. The PMSG converts the mechanical energy into the electrical energy. However, because of the frequency and the amplitude of the PMSG output voltage do not match, the PMSG can not be directly connected to the grid, the PMSG is connected to the power system through a converter. The direct-driven wind turbine control system is responsible for the wind turbine maximum wind energy capture, as well as the amplitude control and the phase control of the converter output voltage. The coordinated operation between the direct-driven wind turbine and the power grid is achieved. Wind speed is the power source of the wind turbine and the wind speed 
PAPER

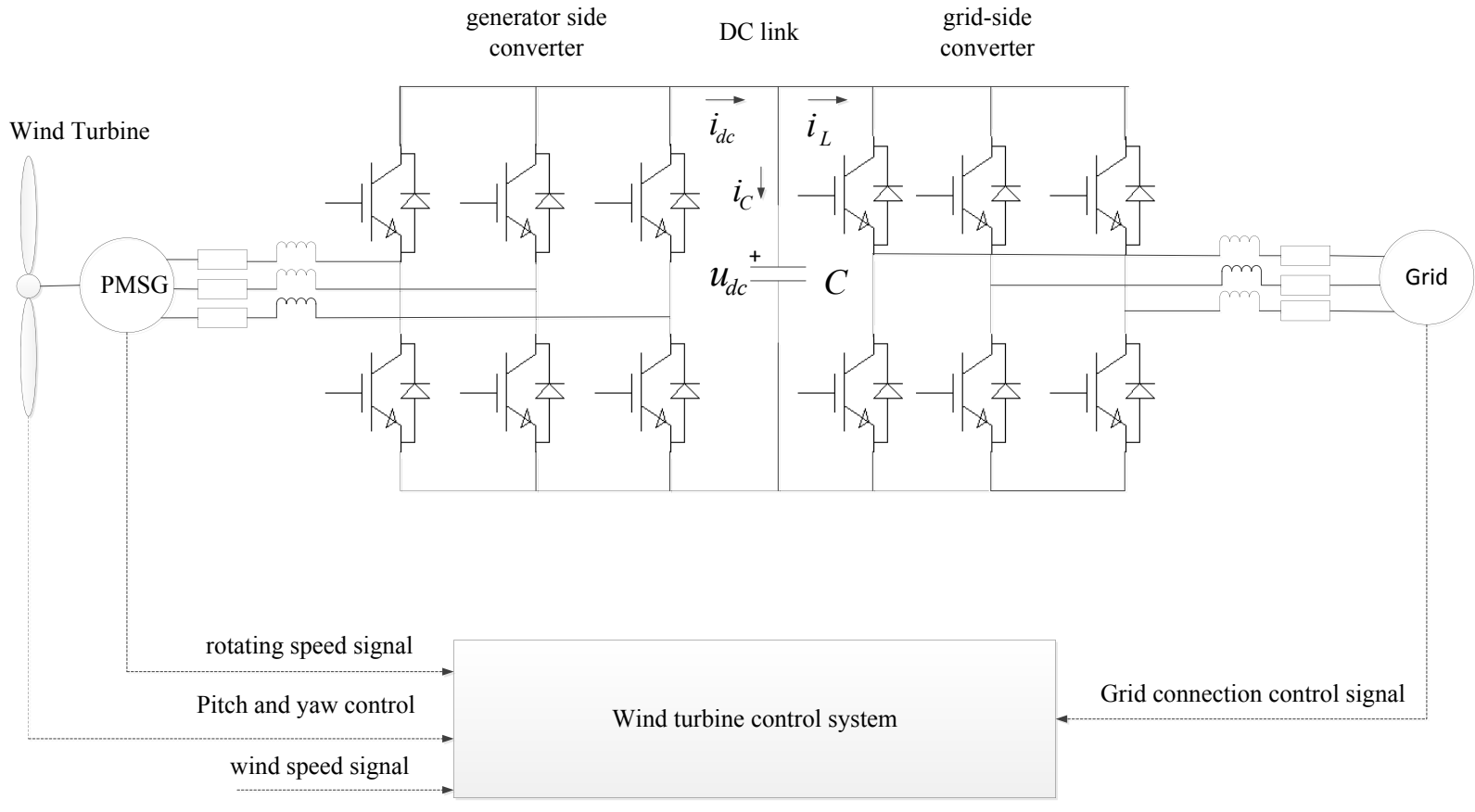

Figure 1 Overall structure of the direct-driven wind turbine

model is the basis for the research of the wind turbine. Wind speed model is studied and analyzed firstly in this paper.

The natural wind speed has random characteristics, and the natural wind speed can be described through the Vander Hoven wind speed spectrum model, As shown in Figure 2.

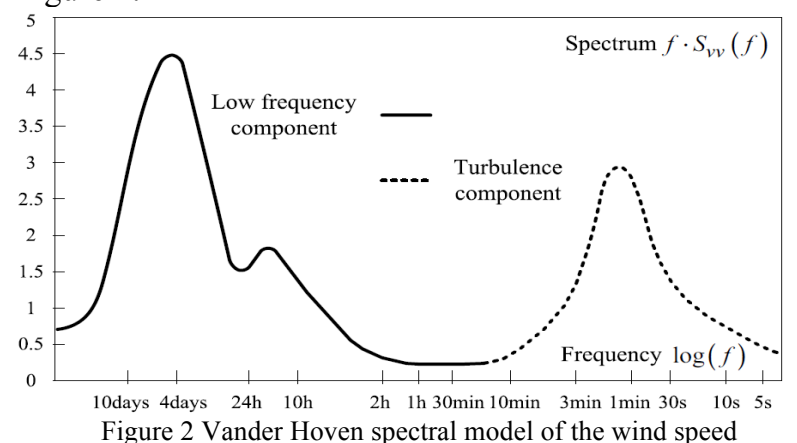

Figure 2 shows that the Vander Hoven wind speed spectrum model is composed of the mid-long term wind speed and the short-time wind speed (the part of the dotted line in Figure 2, the wind speed spectrum curve from the beginning of $10 \mathrm{~min}$ to the right). The short-time wind speed is the main factor influencing the dynamic characteristics of the wind turbine and the wind energy capture efficiency. Therefore, The wind speed model established in the paper is the short-term wind speed model.

The short-time wind speed can be composed of the average wind speed (the average wind speed between the $10 \mathrm{~min}$ to $1 \mathrm{~h}$ ) and the turbulence. The turbulence obeys the gauss normal distribution and the average value of the gauss normal distribution is zero, and the standard of the gauss normal distribution deviation depends on the size of the average wind speed. The calculation formula can be shown as equation (1) .

$$
v(t)=v_{s}(t)+v_{t}(t)
$$

where, $v_{s}(t)$ represents the average wind speed, typically taking $1 \mathrm{~h}$ average wind speed in the calculation; $v_{t}(t)$ represents turbulent. The size of $v_{s}(t)$ affect the magnitude of the turbulence.

The value of $v_{t}(t)$ can be calculated by multiplying the white noise with unit variance and the shaping filter. $S_{v}(w)$ represents power spectral density and the calculation formula is shown as equation (2).

$$
S_{v i}(w)=\left|H_{t}(j w)\right|^{2} \cdot S_{n}(w)
$$

Where, $S_{v}(w)$ represents power spectral density and its value is constant, $\left|H_{t}(j w)\right|$ represents the transfer function of the shaping filter. Von Karman gave the shaping filter transfer function expression, which is shown as equation (3).

$$
H_{t}(j w)=\frac{K_{F}}{\left(1+j w T_{F}\right)^{5 / 6}}
$$

Where, $T_{F}=L_{t} / v_{s}(\mathrm{t})$ represents time constants. $L_{t}$ is chosen according to the Danish standard (DS 4722007), according to the Danish standard, the expression of $L_{t}$ can be shown as equation (4).

$$
L=\left\{\begin{array}{lll}
150 m, & \text { when } & z \geq 30 m \\
5 z m, & \text { when } & \mathrm{z}<30 \mathrm{~m}
\end{array}\right.
$$

$K_{F}$ represents the gain of the transfer function, the calculation formula is shown as equation (5).

$$
K_{F}=\sqrt{\frac{2 \pi}{B(1 / 2,1 / 3)} \frac{T_{F}}{T_{S}}}
$$

Where, $T_{S}$ represents the sampling time of the white noise, which can be configured. $B(x, y)$ represents the beta function. 
The non integer order filter in the Von Karman filter is used in equation (3), the calculation process of the non integer order filter is difficult. Therefore, this article uses the improved Von Karman filter and the improved Von Karman filter has the integer order transfer function. The improved von Karman filter transfer function has the same efficiency with the non integer order filter, but the calculation process becomes simple. The improved filter transfer function expression formula is shown as equation (6).

$$
H_{t}(j w)=K_{F} \frac{j w m_{1} T_{F}+1}{\left(1+j w T_{F}\right)\left(j w m_{2} T_{F}+1\right)}
$$

Where, $m_{1}=0.4, m_{2}=0.25$.

Based on the above knowledge, the calculation process of the turbulence can be shown as Figure 3.

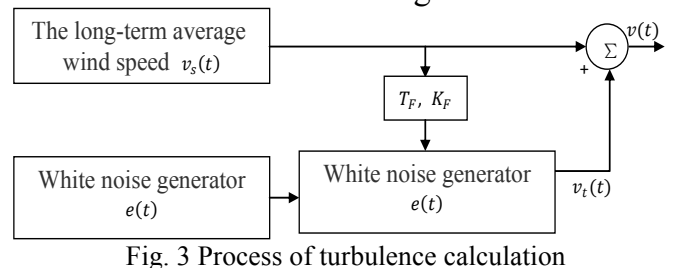

Figure 4 is the $10 \mathrm{~s}$ turbulent wind speed generated by the turbulence model. It is can be known from Figure 4 that the turbulence fluctuation amplitude is related to the size of the average wind speed $v_{s}(t)$. The $v_{s}(t)$ is smaller, the turbulence fluctuation also is smaller; When the $v_{s}(t)$ is bigger, the turbulence fluctuation is bigger too. The conclusion is consistent with theoretical knowledge.

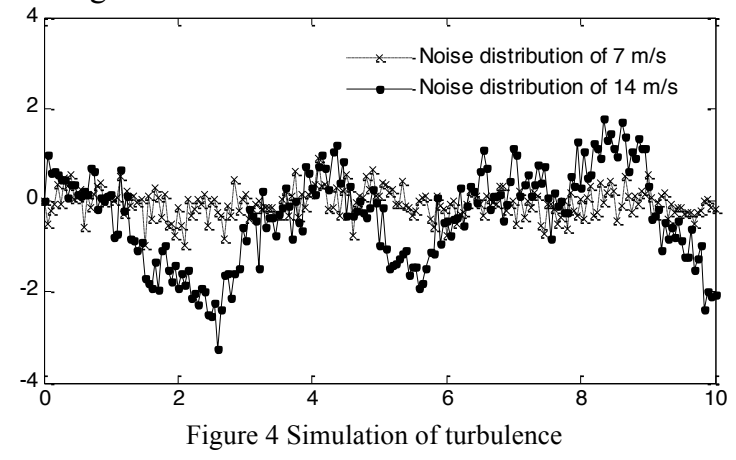

Figure 5 shows the statistical characteristics of the turbulence. It can be known that the turbulence obeys the Gauss normal distribution, and standard deviation $\sigma$ depends on the size of the average wind speed $v_{s}(t)$. When the average wind speed is $14 \mathrm{~m} / \mathrm{s}$, the standard deviation $\sigma$ is greater than the standard deviation of the average speed $7 \mathrm{~m} / \mathrm{s}$. The above simulation results prove the correctness of the established turbulence model.

\section{MATHEMATICAL MODEL OF THE AERODYNAMIC}

Rotor is the device to convert wind energy into mechanical energy. The conversion relation is shown as equation (7) .

$$
P_{W T}=\frac{1}{2} \rho \pi R^{2} v^{3} C_{p}(\beta, \lambda)
$$

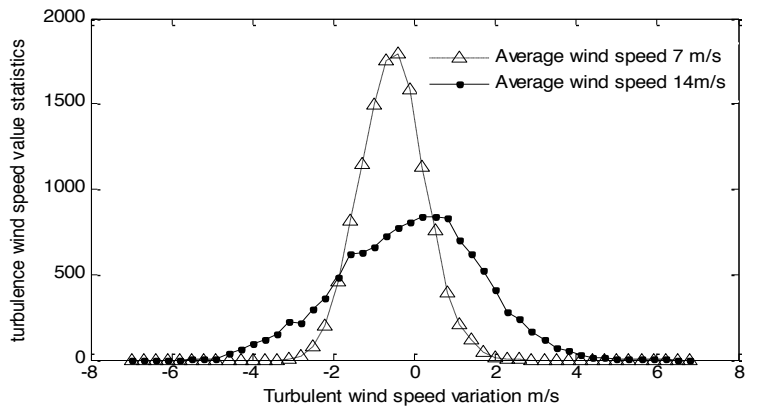

Figure 5 Statistical characteristics of turbulence

Where, $P_{V T}$ represents the mechanical power of the wind turbine; $\rho$ represents the air density; $R$ represents the rotor radius; $v$ represents the wind speed; $\beta$ represents the pitch Angle; $\lambda$ represents tip speed ratio; $C_{p}$ represents the wind energy use efficiency. The relationship among $C_{p}, \lambda$ and $\beta$ is shown as equation (8).

$$
\left\{\begin{aligned}
C_{p}(\beta, \lambda) & =0.22\left(\frac{116}{\lambda_{i}}-0.4 \beta-5\right) e^{-\frac{22.5}{\lambda_{i}}} \\
\frac{1}{\lambda_{i}} & =\frac{1}{\lambda+0.08 \beta}-\frac{0.035}{\beta^{3}+1}
\end{aligned}\right.
$$

Figure 6 illustrate the relationship among $C_{p}, \lambda$ and $\beta$. This paper mainly studies the dynamic characteristics of the direct-driven wind turbine. In order to facilitate the analysis of the main problems, the directdriven wind turbine is running below the rated wind speed and the pitch angle is 0 degrees in the study process. Under this assumption, the size of $C_{p}$ is associated with $\lambda$ only.

\section{MATHEMATICAL MODEL OF THE GENERATOR CONTROL SYSTEM}

The voltage $(a, b, c)$ three coordinate system can be transformed into $(\mathrm{d}, \mathrm{q})$ two coordinate system through the Park transform. The transformed coordinate system $(\mathrm{d}, \mathrm{q})$ is shown as equation (9).

$$
\left\{\begin{array}{l}
u_{d}=R i_{d}+L_{d} i_{d}^{\prime}-\Phi_{q} \omega_{S} \\
u_{q}=R i_{q}+L_{q} i_{q}^{\prime}+\Phi_{d} \omega_{S}
\end{array}\right.
$$

Where $R$ represents the stator resistance; $u_{d}$ and $u_{q}$ represent $\mathrm{d}$ axis and $\mathrm{q}$ axis stator voltage component respectively; $L_{d}$ and $L_{q}$ represent $\mathrm{d}$ axis and $\mathrm{q}$ axis inductance respectively; $\omega$ s represents the stator frequency; $\Phi_{d}$ and $\Phi_{q}$ represent $\mathrm{d}$ axis and $\mathrm{q}$ axis magnetic flux respectively; $\Phi_{d}$ and $\Phi_{q}$ can be calculated from equations (10) and (11).

$$
\begin{gathered}
\Phi_{d}=L_{d} i_{d}+\Phi_{m} \\
\Phi_{q}=L_{q} i_{q}
\end{gathered}
$$

In equation (10), $\Phi_{m}$ is determined by the permanent magnet constant flux.

The equation (12) can be obtained to take equations (10) and (11) into equation (9). 


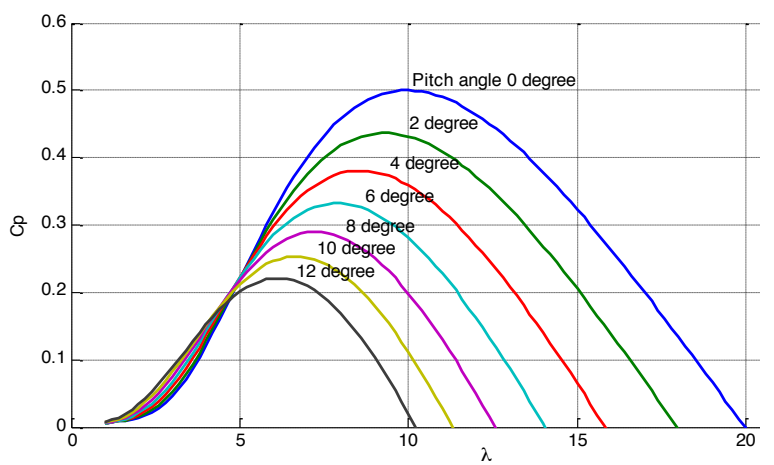

Figure 6 Calculation relation of $C_{p}, \beta$ and $\lambda$

$$
\left\{\begin{array}{l}
u_{d}=R i_{d}+L_{d} i_{d}^{\prime}-L_{q} i_{q} \omega_{S} \\
u_{q}=R i_{q}+L_{q} i_{q}^{\prime}+\left(L_{d} i_{d}+\Phi_{m}\right) \omega_{S}
\end{array}\right.
$$

The electromagnetic torque can be calculated by equation (13).

$$
\Gamma_{\mathrm{G}}=p\left(\Phi_{d} i_{q}-\Phi_{q} i_{d}\right)=p\left[\Phi_{m} i_{q}+\left(L_{d}-L_{q}\right) i_{d} i_{q}\right]
$$

Where, ${ }^{p}$ represents the number of pole pairs. If the permanent magnet is installed in the rotor surface, then $L_{d}=L_{q}$. The equation (13) can be simplified as equation (14).

$$
\Gamma_{\mathrm{G}}=p \Phi_{m} i_{q}
$$

When the generator connected to the grid, the equation (12) is turned into equation (15).

$$
\left\{\begin{array}{l}
u_{d}=-R i_{d}-L_{d} i_{d}^{\prime}+L_{q} \Phi_{q} \omega_{S} \\
u_{q}=-R i_{q}-L_{q} i_{d}^{\prime}-\left(L_{d} i_{d}-\Phi_{m}\right) \omega_{S}
\end{array}\right.
$$

The stator frequency $\omega$ s is proportional to the shaft speed, namely $\omega s=p \Omega_{h}$. The equation (15) can be expressed as equation (16).

$$
\left\{\begin{array}{l}
x=\left[\begin{array}{ll}
x_{1}(t) & x_{2}(t)
\end{array}\right]^{T} \equiv\left[\mathrm{i}_{d}(t) i_{q}(t)\right]^{T} \\
u=\left[\begin{array}{ll}
u_{d} & u_{q}
\end{array}\right]
\end{array}\right.
$$

Therefore, the PMSG model connected to the power grid can be represented by equation (17).

$$
\left\{\begin{array}{l}
x^{\prime}=\left[\begin{array}{l}
-\frac{R}{L_{d}} x_{1}+p \frac{L_{q}}{L_{d}} x_{2} \Omega_{h} \\
-\frac{R}{L_{d}} x_{1}-p \frac{L_{d} x_{1}-\Phi_{m}}{L_{q}} \Omega_{h}
\end{array}\right] x+\left[\begin{array}{cc}
-\frac{1}{L_{d}} & 0 \\
0 & -\frac{1}{L_{q}}
\end{array}\right] u \\
y \equiv \Gamma_{G}=p \Phi_{m} x_{2}
\end{array}\right.
$$

The simulation model of the generator control system is shown as figure 7 .

\section{MATHEMATICAL MODEL OF THE GRID SIDE CONVERTER}

For direct-driven wind turbine, the grid side converter works in the inverter mode. The voltage and the current of the inverter complies with the requirements of the AC network.

Figure 8 is a direct-driven wind turbine grid side threephase voltage source inverter structure diagram. $L_{g}$ represents grid side filter inductor parameters, $R_{g}$ represents grid side line resistance. For the grid side, the inductance equivalent impedance is far greater than the resistance value. In the control system design, the impact of $R_{g}$ on the control system is negligible. The DC voltage source $u_{d c}$ is on behalf of the grid side inverter DC bus voltage. During the model building process, the three-phase grid voltage are assumed symmetrical and stable. The switch components in the circuit are the ideal switch. The DC bus voltage $u_{d c}$ maintains constant. The grid side filter inductor $L_{g}$ has a linear characteristic and without considering the saturation.

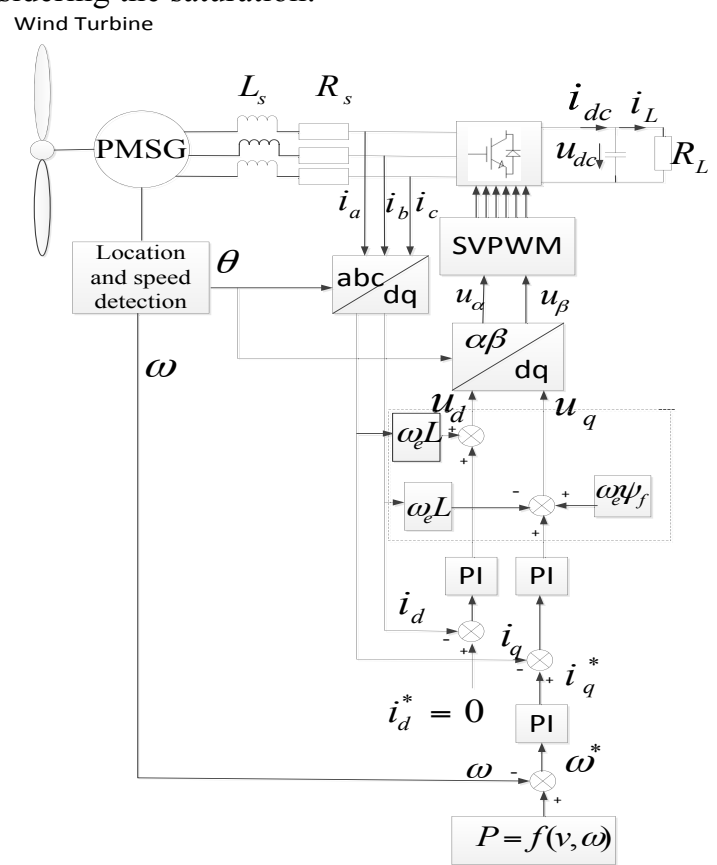

Figure 7 Control model of the generator

Based on the above conditions, the mathematical expression of the grid connected inverter is analyzed. The provisions of the two valued logic switch function is $S_{k}$.

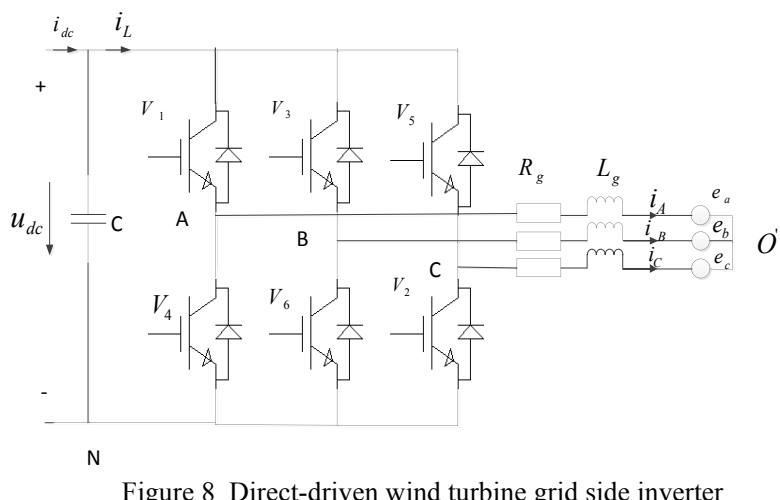

$$
S_{k}=\left\{\begin{array}{ll}
1 & \text { upper conduction, under off } \\
0 & \text { upper off, } \text { under conduction }
\end{array}(k=A, B, C)\right.
$$

Equation (19) can be got according to the switching function.

$$
\left\{\begin{array}{l}
u_{A N}=u_{d c} S_{A}=u_{A o^{\prime}}+u_{O^{\prime} N}=R_{g} i_{A}+L_{g} \frac{d i_{A}}{d t}+e_{a}+u_{O^{\prime} N} \\
u_{B N}=u_{d c} S_{B}=u_{B o^{\prime}}+u_{O^{\prime} N}=R_{g} i_{B}+L_{g} \frac{d i_{B}}{d t}+e_{b}+u_{O^{\prime} N} \\
u_{C N}=u_{d c} S_{C}=u_{C o^{\prime}}+u_{O^{\prime} N}=R_{g} i_{C}+L_{g} \frac{d i_{C}}{d t}+e_{c}+u_{O^{\prime} N}
\end{array}\right.
$$


Because the three-phase grid voltage is symmetrical and stability, so $i_{A}+i_{B}+i_{C}=0$ and $e_{a}+e_{b}+e_{c}=0$. Equation (20) can be got from equation (19).

$$
u_{O^{\prime} N}=\frac{1}{3}\left(S_{A}+S_{B}+S_{C}\right) u_{d c}
$$

Equation (21) can be got to take equation (20) into equation (19).

$$
\left\{\begin{array}{c}
L_{g} \frac{d i_{A}}{d t}=-R_{g} i_{A}-e_{a}+\left[S_{A}-\frac{\left(S_{A}+S_{B}+S_{C}\right)}{3}\right] u_{d c} \\
L_{g} \frac{d i_{B}}{d t}=-R_{g} i_{B}-e_{b}+\left[S_{B}-\frac{\left(S_{A}+S_{B}+S_{C}\right)}{3}\right] u_{d c} \\
L_{g} \frac{d i_{C}}{d t}=-R_{g} i_{C}-e_{c}+\left[S_{C}-\frac{\left(S_{A}+S_{B}+S_{C}\right)}{3}\right] u_{d c} \\
C \frac{d u_{d c}}{d t}=-S_{A} i_{A}-S_{B} i_{B}-S_{C} i_{C}+i_{d c}
\end{array}\right.
$$

The state equation of equation (21) is shown as equation (22).

$$
\frac{d}{d t}\left[\begin{array}{l}
i_{A} \\
i_{B} \\
i_{C}
\end{array}\right]=\left[\begin{array}{ccc}
-\frac{R_{g}}{L_{g}} & 0 & 0 \\
0 & -\frac{R_{g}}{L_{g}} & 0 \\
0 & 0 & -\frac{R_{g}}{L_{g}}
\end{array}\right]\left[\begin{array}{l}
i_{A} \\
i_{B} \\
i_{C}
\end{array}\right]+\left[\begin{array}{l}
\frac{u_{d c}}{L_{g}}\left(S_{A}-\frac{1}{3} \sum_{k=a, b, c} S_{k}-\frac{e_{a}}{L_{g}}\right) \\
\frac{u_{d c}}{L_{g}}\left(S_{B}-\frac{1}{3} \sum_{k=a, b, c} S_{k}-\frac{e_{b}}{L_{g}}\right) \\
\frac{u_{d c}}{L_{g}}\left(S_{C}-\frac{1}{3} \sum_{k=a, b, c} S_{k}-\frac{e_{c}}{L_{g}}\right)
\end{array}\right]
$$

The state equation of PWM inverter can be got in (d, q) coordinate system by rotating the coordinate transformation, which is shown as equation (23).

$$
\left[\begin{array}{c}
\frac{d i_{s d}}{d t} \\
\frac{d i_{s q}}{d t}
\end{array}\right]=\left[\begin{array}{cc}
-\frac{R_{g}}{L_{g}} & \omega \\
-\omega & -\frac{R_{g}}{L_{g}}
\end{array}\right]\left[\begin{array}{l}
i_{s d} \\
i_{s q}
\end{array}\right]+\left[\begin{array}{l}
\frac{1}{L_{g}}\left(S_{s d} u_{d c}-e_{d}\right) \\
\frac{1}{L_{g}}\left(S_{s q} u_{d c}-e_{q}\right)
\end{array}\right]
$$

In equation (23), $\omega$ is the grid angular frequency; $e_{d}$ and $e_{q}$ are the grid voltage of $\mathrm{d}$ and q-axis component; $i_{s d}$ and $i_{s q}$ are the grid current of $\mathrm{d}$ and q-axis component; $S_{s d}$ and $S_{s q}$ are d and q-axis switching function respectively. The inverter output AC voltage satisfy equation (24).

$$
\begin{aligned}
& u_{q}=S_{s q} \cdot u_{d c} \\
& u_{d}=S_{s d} \cdot u_{d c}
\end{aligned}
$$

\section{SySTEM ANALYSIS}

According to the mathematical model of the aforementioned direct-driven wind turbine, the directdriven wind turbine control system structure is constructed, which is shown as Figure 9.

The control system is modeled and analyzed, the model parameters are shown in Table 1.

Table 1 PMSG parameters

\begin{tabular}{|c|c|c|}
\hline Parameter & Symbol & Value \\
\hline Rated generated power & $\mathrm{P}_{\mathrm{g}}$ rated & $2 \mathrm{MW}$ \\
\hline Rated mechanical Speed & $\mathrm{W}_{\mathrm{g}}$ rated & 2.18 \\
\hline Stator resistance & $\mathrm{R}_{\mathrm{s}}$ & $0.08 \Omega$ \\
\hline Stator $d$-axis inductance & $\mathrm{L}_{\mathrm{ds}}$ & $0.334 \mathrm{H}$ \\
\hline Stator $q$-axis inductance & $\mathrm{L}_{\mathrm{gs}}$ & $0.217 \mathrm{H}$ \\
\hline Stator leakage inductance & $\mathrm{L}_{\mathrm{is}}$ & $0.0334 \mathrm{H}$ \\
\hline Permanent magnet flux & $\Psi_{\mathrm{f}}$ & $0.4832 \mathrm{~Wb}$ \\
\hline Pole pairs & $\mathrm{P}$ & 3 \\
\hline
\end{tabular}

The direct-driven wind turbine dynamic characteristic is simulated and analyzed using the constructed model. Figure 10 is the direct-driven wind turbine stator output voltage. In the simulation process, the grid voltage drops to $90 \mathrm{KV}$ from $120 \mathrm{KV}$ within $0.03-0.13$ seconds, the system is back to normal at 0.13 seconds after. Figure 10 shows that the direct-driven wind turbine output voltage also reduces with the grid voltage dropping. When the

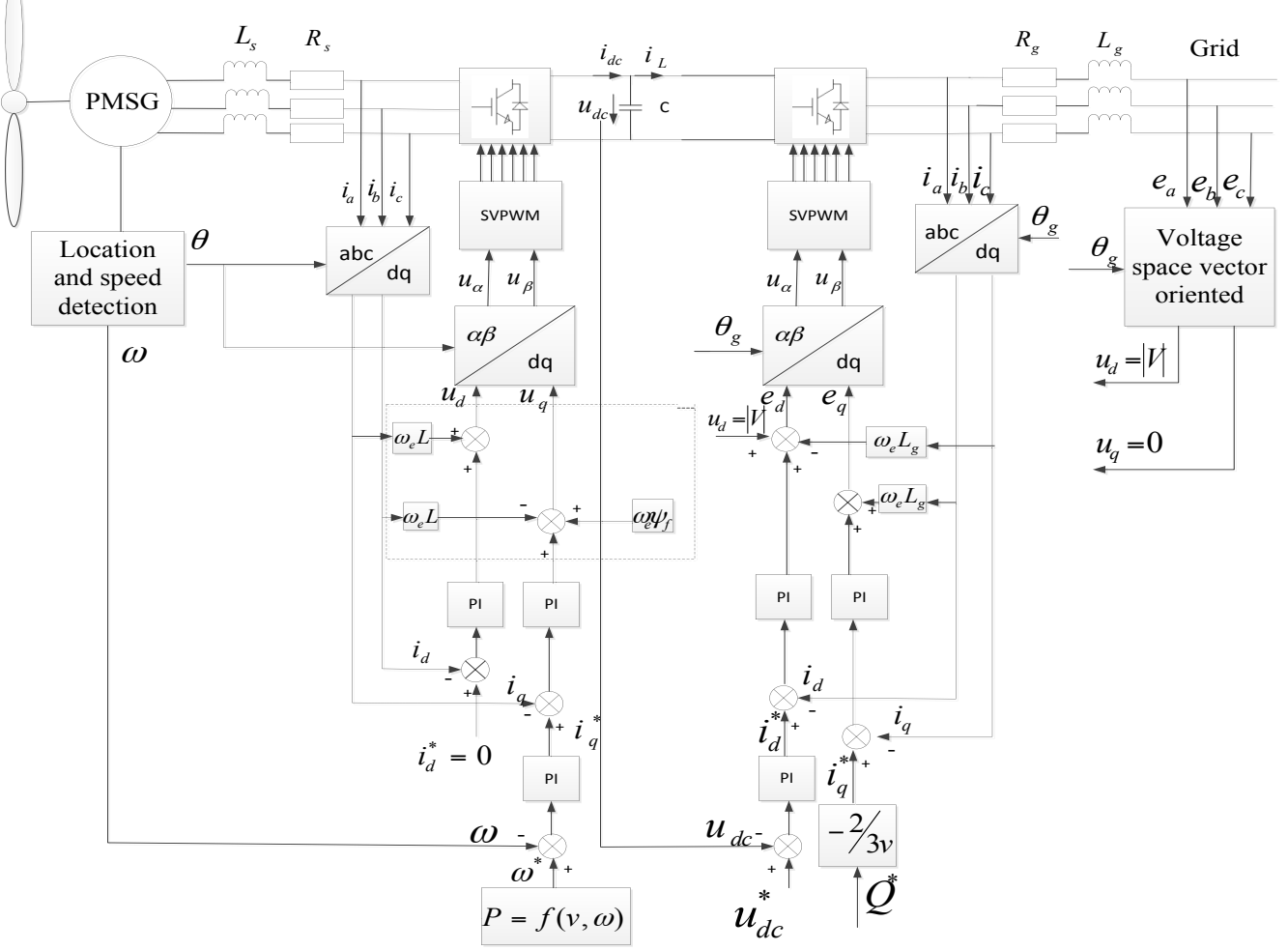

Figure 9 Direct-driven wind turbine machine side control svstem 
system returns to normal, the direct-driven wind turbine output voltage immediately returned to normal. The direct-driven wind turbine model can accurately reflect the change process of the grid voltage.

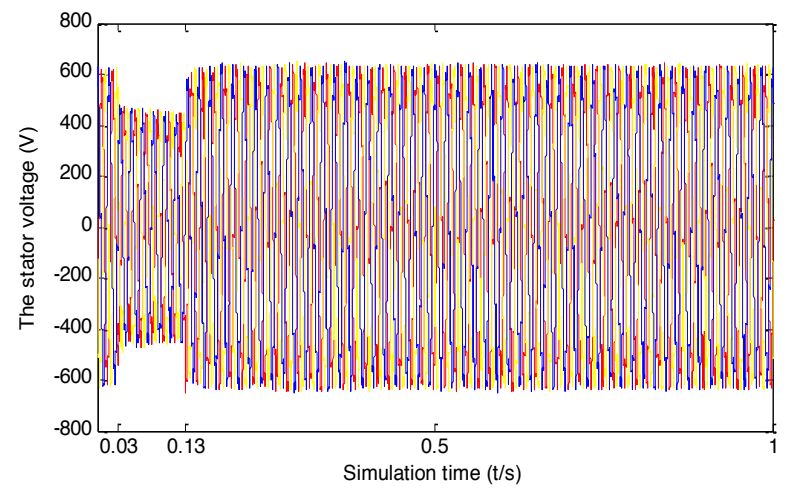

Figure 10 Stator output voltage

Figure 11 is the direct-driven wind turbine stator output current. Figure 11 shows that the generator stator output current increases within $0.03-0.13$ seconds. The generator stator output current increases mainly because the direct-driven wind turbine in order to maintain the stability of the output voltage of the stator end in this period. The reactive power output is increased, resulting in the direct-driven wind turbine output current increases. In 0.13 seconds later, the grid voltage returns to normal, but the generator output current requires a response time to return to normal, this is because of the lag of the direct-driven wind turbine power output control system response time.

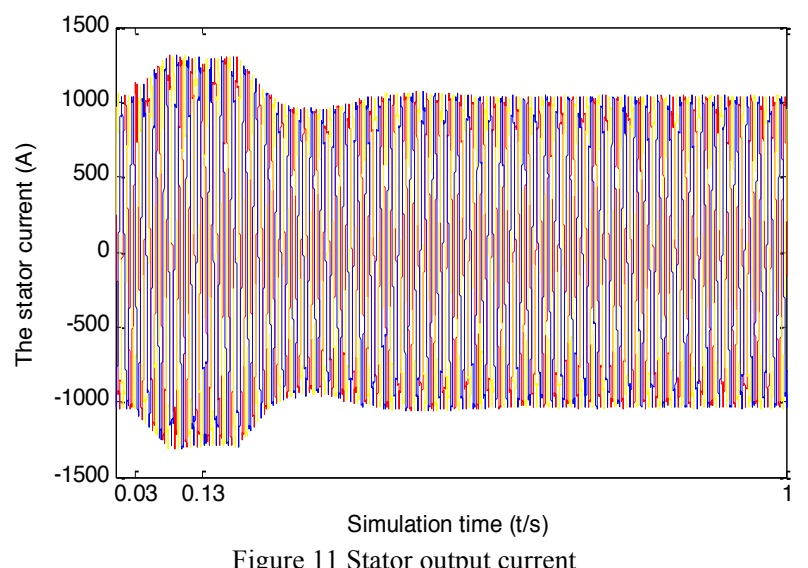

Figure 12 is the direct-driven wind turbine output active power. It is can be seen from Figure 12 that the direct-driven wind turbine output active power reduces within $0.03-0.13$ seconds. In 0.13 second later, the grid voltage returns to normal, but the generator output active power requires a response time to return to normal, this is because of the lag of the direct-driven wind turbine active power output control system response time.

Figure 13 is the DC bus voltage of the direct-driven wind turbine. It is can be seen from Figure 13 that the DC bus voltage increases mainly due to the increasing of the direct-driven wind turbines output reactive power within
0.03-0.13 seconds. In 0.13 seconds later, the grid voltage returns to normal, the DC bus voltage fluctuates a period time before to return to normal, this is because of the lag of the DC bus control system response time.

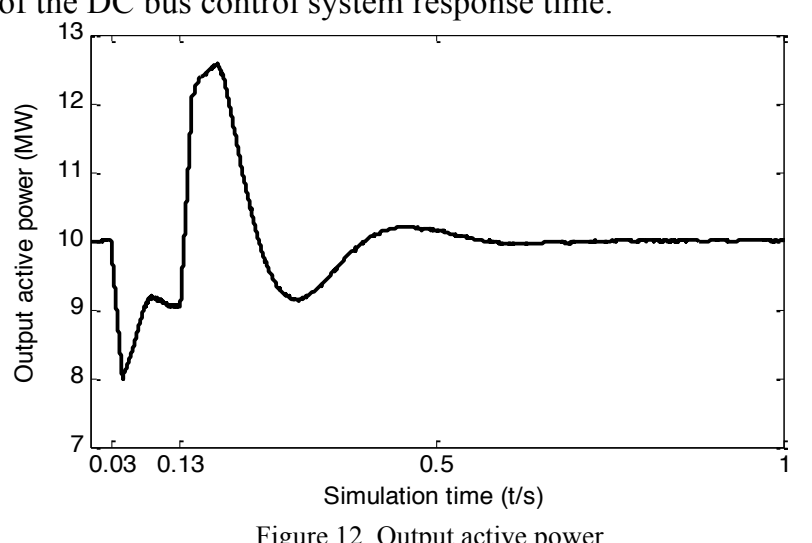

Figure 12 Output active power

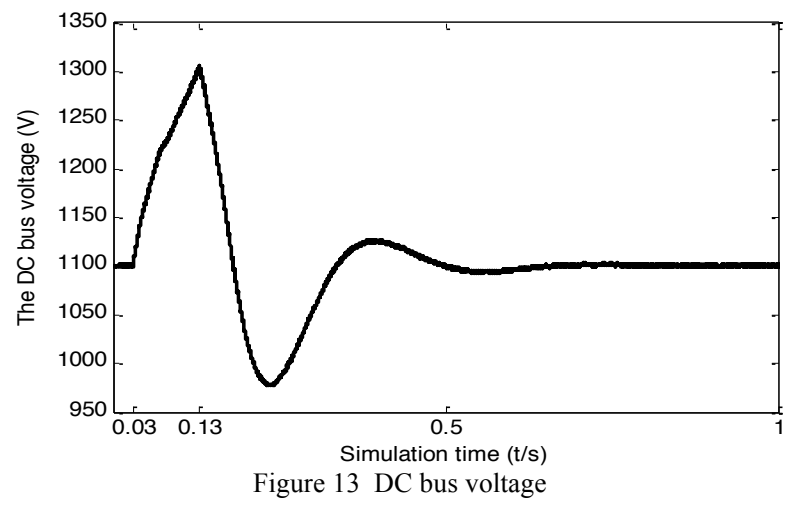

VII. CONCLUSIONS

The system structure of the direct-driven wind turbine was analyzed in the paper. The mathematical model of the direct-driven wind turbine all major subsystems, including wind speed model, aerodynamic model generator model, the grid-side converter model were established. Based on these subsystems, the whole model of the direct-driven wind turbine was established by integrating the various subsystem mathematical model.

The whole model of the direct-driven wind turbine was modeled and analyzed, the simulation results indicate that the direct-driven wind turbine model can accurately reflect the dynamic characteristics of the wind turbine operation process. The study of the paper provides support for studying the wind turbine operating principles and improving wind turbine operating efficiency.

\section{ACKNOWLEDGMENT}

This work is supported by Henan provincial key science and technology projects (142102210059). In the research process, there are some people who have made a certain contribution for the work, but their name are not listed in the paper, we must say thank you.

\section{REFERENCES}

[1] A. Rolan, A. Luna, G. Vazquez, G. Azevedo. "Modeling of a Variable Speed Wind Turbine with a Permanent Magnet 
PAPER

Simulation AND ANALYSIS OF DiRECT-DRIVEN WIND TURBINE

Synchronous Generator", IEEE International Symposium on Industrial Electronics, (2009) July 5-8, Seoul, Korea. http://dx.doi.org/10.1109/isie.2009.5218120

[2] H. W. Kim, S. S. Kim, H. S. Ko. "Modeling and Control of PMSG-based Variable-speed Wind Turbine", Electric Power Systems Research, V. 80, 2010, pp.46-52. http://dx.doi.org/10.1016/j.epsr.2009.08.003

[3] A. B. Sankar, D. R. Seyezhai. "MATLAB Simulation of Power Electronic Converter for PMSG Based Wind Energy Conversion System", International Journal of Innovative Research in Electrical, Electronics, Instrumentation and Control Engineering, Vol.1, 2013, pp. 348-353.

[4] H. Ye, J. Su, S. H. Du. "Simulation and Analysis of PMSG-based Wind Energy Conversion System using Different Converter Models", Engineering, V. 5, 2013, p. 96-100. http://dx.doi.org/10.4236/eng.2013.51B017

[5] R. K. Tiwari, K. K. Sharma. "Simulation and Modeling of Wind Turbine using PMSG", International Journal of Recent Research and Review, V. 7, 2014, pp. 46-50.

[6] S. Samanvorakij, P. Kumkratug. "Modeling and Simulation PMSG based on Wind Energy Conversion System in MATLAB/SIMULINK", Proc. of the Second Intl. Conf. on Advances in Electronics and Electrical Engineering, 2013, Bangkok, Thailand.

[7] N. S. Jayalakshmi, D. N. Gaonkar, K. S. K. Kumar. "Dynamic Modeling and Performance Analysis of Grid Connected PMSG based Variable Speed Wind Turbines with Simple Power Conditioning System", 2012 IEEE International Conference on Power Electronics, Drives and Energy Systems, 2012 16-19, Bengaluru, India. http://dx.doi.org/10.1109/pedes.2012.6484474
[8] D. Mary, S. Mathew, K. Sreejith. "Modeling and Simulation of Grid Connected Wind Energy System", International Journal of Soft Computing and Engineering, 2013, p. 255-259.

[9] C. Janani, K. Rajambal. "Modeling and Performance Analysis of a Small Scale Direct Driven PMSG Based Wind Energy Conversion Systems", Journal of Energy Technologies and Policy, V. 1, 2011, p. 8-19.

[10] A. M. Hemeida, W. A. Farag, O. A. Mahgoub. "Modeling and Control of Direct Driven PMSG for Ultra Large Wind Turbines, World Academy of Science", Engineering and Technology, V. 5, 2011, p. 546-551.

\section{AUTHORS}

Hu Hao received the Master degree in North China University of Water Resources and Electric Power in 2008. Currently, he is a lecturer at North China University of Water Resources and Electric power, At same time, he is a $\mathrm{PhD}$ student of North China Electric Power University. His interests are in new energy generation technologies. The contact address is Henan 450011, china (e-mail: hh@ ncwu.edu.cn).

Gu Bo received the Master degree in North China University of Water Resources and Electric Power in 2006. Currently, he is a lecturer at North China University of Water Resources and Electric power, Henan 450011, china (e-mail:gb19820915@163.com). 